\title{
Prevalence of obesity in Kazakhstan
}

\section{Roman Fursov $1,2,3$, Oral Ospanov ${ }^{1,2,3}$, and Alexandr Fursov $2,3,4,5$}

1. Department of Endosurgery, Medical University of Astana, Astana, Kazakhstan

2. Society of Bariatric and Metabolic Surgeons of Kazakhstan

3. Kazakhstan Association of Endoscopic Surgeons

4. Department of General Surgery, Medical University of Astana, Astana, Kazakhstan

5. European Academy of Natural History

\section{BRIEF REPORT}

Please site this paper as: Fursov R, Ospanov O, Fursov A. Prevalence of obesity in Kazakhstan. AMJ 2017;10(11):916920. https://doi.org/10.21767/AMJ.2017.3169

\section{Corresponding Author:}

\section{Roman Fursov}

Department of Endosurgery, Medical University of Astana Beibitshilik street 49A, Astana, Kazakhstan, 010000

Email: fursrom@mail.ru

\section{ABSTRACT}

\section{Background}

Obesity is a growing problem throughout the world, including Kazakhstan. However, the obesity rate in interconnection with diabetes and geographical features of the Kazakhstan, has not been investigated yet.

\section{Aims}

To scrutinize the spatial rates of obesity in various regions of Kazakhstan.

\section{Methods}

Investigations are epidemiological, continuous (covering the entire territory of the state). They are carried out by means of mass medical examination. In addition, the studies are descriptive (descriptive-evaluative) and analytical. Statistic data have been selected in accordance with the following criteria: the diagnosed cases of obesity, diabetes, the demographic survey in the country during the last 5 years; the morbidity rate per 100,000 population.

\section{Results}

The population increase over 5 years of the research turned out to be over 1.3 million people or 7.97 per cent. The annual growth rate, on average, amounted to 1.59 per cent. The total morbidity for all classes of diseases listed in "ICD10 " over the five-year period increased only by 1 per cent. However, morbidity related to endocrinological disorders, malnutrition and metabolic disorders (E00-E89) increased significantly by 19.7 per cent.

\section{Conclusion}

The investigation revealed a stable growth in obesity, diabetes, metabolic and nutritional disorders. The annual increase in obesity rates during the study period amounted to 3.9 per cent. The highest correlation (Pearson) of obesity value and diabetes is $(r, 0.96)$. South-Kazakhstan, Astana city and Almaty city were identified as the regions with the highest obesity rates.

The identified regional features of obesity should help the healthcare system of Kazakhstan organize targeted arrangements to reduce the growth of this pathology.

\section{Key Words}

Prevalence, obesity, diabetes

\section{Implications for Practice:}

\section{What is known about this subject?}

The obesity rate in interconnection with diabetes and geographical features of the Kazakhstan, has not been investigated yet.

\section{What new information is offered in this report?}

The investigation revealed a stable growth in obesity, diabetes, metabolic and nutritional disorders.

3. What are the implications for research, policy, or practice?

The identified regional features of obesity should help the healthcare system of Kazakhstan organize targeted arrangements to reduce the growth of this pathology. 


\section{Background}

Obesity presents an increasing threat to health throughout the world including Kazakhstan. Overweight and obesity are defined as abnormal or excessive fat accumulation that can have negative impact on health. ${ }^{1}$ Population of those having BMI reaches or exceeds $25-30 \mathrm{~kg} / \mathrm{m}^{2}$ is steadily rising along with the growth of patients with endocrine disorders. According to National Genetic Register, up to 30,000 patients with endocrine pathology are recorded annually, majority of whom are diabetic. ${ }^{2}$ Finding of the 5th National Research in Kazakhstan indicated that 31.2 per cent of adults suffered from obesity ${ }^{3}$ whereas international observers reported obesity rate in Kazakhstan at 23.5 per cent. ${ }^{4}$

However, incidence of obesity, its relation to endocrine disorders, nutrition habits and demographic or geographic features has not been investigated yet.

\section{Case details}

Investigations are epidemiological, continuous (covering the entire territory of the state). They are carried out by means of mass medical examination. In addition, the studies are descriptive (descriptive-evaluative) and analytical.

The body of data included the total number of population living in the country in respect of the demographic growth. Cases of morbidity on the studied nosology and in the regions of Kazakhstan came to be in the test group. The morbidity was investigated by means of retrospective and prospective method.

Statistic data has been selected in accordance with the following criteria: the diagnosed cases of obesity, diabetes, the demographic survey in the country during the last 5 years; the morbidity rate per 100,000 population. Height and weight data were measured by medical staff.

The processing of information was carried out with the help of "Medstat" and "Statistica 10" software. The information was taken into account from the statistic registers of all governmental and non-governmental medical outpatient hospitals and clinics, hospitals. During the statistic processing of information, quantitative and qualitative statistical features were identified. Quantitative features: the morbidity rate and its dynamics, the rate distribution from 2011-2016. Qualitative features: the general distribution of patients across the territory of the state, regions, among urban and rural populations in respect of age, gender and other characteristics. Continuous variables are expressed as the mean \pm standard deviation. The chisquare test was used to test differences in categorical variables between the cases and controls, and analysis of variance (ANOVA) or the Student's t-test was used for comparisons of continuous variables. Spearman's rank correlation and univariate regression analysis were used to determine the strength of the relationship between obesity and diabetes. A significance level of $p<0.001$ was used in this test.

According to the research, in respect of the state statistics in 2016, 4,050 medical organizations were registered in Kazakhstan including outpatient - polyclinics $-3,149$ and hospitals -901 .

Taking into account the significance of reliable data on the number of patients and diseases, a targeted screening was carried out from all regions of Kazakhstan. Data on metabolism disorders, causing overweight and obesity, endocrine diseases and diabetes, was selected and categorized. The results were taken into account both in absolute numbers and per 100,000 people of the population.

Besides this, the dynamics of demographic growth in Kazakhstan and its relationship with the population health rates were determined. It was revealed that the number of population by January 1,2011 amounted to $16,442,500 .^{5}$

However, at the end of 2016, the population reached over $17,754,100$. Urban population (54.1 per cent) prevails over rural (45.9 per cent).$^{5-8}$ In addition, the population increase over 5 years of the research turned out to be over 1.3 million people or 7.97 per cent. The annual growth rate, on average, amounted to 1.59 per cent.

The total morbidity for all classes of diseases listed in "ICD$10^{\prime \prime}$ over the five-year period increased only by 1 per cent. However, morbidity related to endocrinological disorders, malnutrition and metabolic disorders (E00-E89) increased significantly by 19.7 per cent. If this rate is compared with the population growth, it turns out that it exceeds it by almost 2.5 times (7.97 per cent vs. 19.7 per cent). Moreover, with further analysis of the statistical results (in terms of 100,000 people), it turned out that the endocrine morbidity with malnutrition and metabolic disorders increased by 13 per cent namely from 3,745.1 to 4,232.7.

The data analysis received from various regions of Kazakhstan illustrated that the morbidity of diabetes and 
patients with obesity (the number of diseases registered for the first time, per 100,000 people) is gradually increasing.

In addition, the dynamics of obesity growth in cities were significantly higher than in rural areas. Conversely, the specific gravity of diabetes and obesity in relation to the total morbidity (in percentage) among the urban population turned out to be lower than that of rural areas.

According to the official data (published in the statistical volume on health in 2016), the average morbidity of diabetes in Kazakhstan was 168.6 (per 100,000 people). However, the morbidity of obesity in relation of overweight people was 176.7 (per 100,000). These incidence rates of diabetes and obesity in the regions of Kazakhstan were calculated and presented by the regional boards. According to the results of our additional analysis in relation of 2016, the incidence rates turned out to be somewhat higher. For instance, the incidence rate of diabetes in early 2016 was 180.7 (per 100,000 people). But the morbidity of obesity, without consideration of overweight patients, rose to the level of 91.2 (per 100,000 people) (Table 1).

The annual increase in obesity (R., per cent) in Kazakhstan for the period of our observation amounted to an average of 3.9. Moreover, it depicted a steady trend notwithstanding the negative dynamics in some regions, for example, West Kazakhstan in Mangystau and North Kazakhstan in Pavlodar showed decline, at -3.0 and -3.7 per cent respectively. Obesity growth confirms a constant increase of the morbidity per 100,000 people.

\section{Discussion}

The results of a five-year investigation, such as the incidence rate distinction in rural and urban areas, uneven correlation of diabetes rate with the obesity growth, the different rates of obesity growth in Kazakhstani regions can be estimated as somewhat paradoxical. However, to explain it, it is necessary to take into consideration the following peculiarities of the states's development. Successively, these peculiarities affect the healthcare development and the formation of a morbidity prevention system and related risks.

Firstly, the specific gravity of identified patients in rural areas is increasing as a result of the extensive and intensive activities of medical staff. Moreover, it is because of the active identification of overweight people and their inclusion in statistical reports (where many patients were not registered).
Secondly, this process occurs because of intensive migration of the population from rural areas to large cities and it increases the total number of people (including healthy and sick people) in absolute numbers. ${ }^{9}$ For instance, there were $8,961,336$ people in the cities of Kazakhstan in 2011. In 2016 , it amounted to over $10,066,500$ people. Furthermore, the treatment rate of patients to medical organizations in the cities is traditionally higher, which also affects the statistical data.

The results of studying correlation Pearson depicted that obesity rates are closely related to diabetes mellitus. The highest correlation ( $r$ ) was in 2011 (0.97). In 2016, it decreased slightly (0.96). Moreover, comparing the level of obesity correlation in the regions and observation years, the rate $(r)$ turned out to be 0.83 . Calculation and comparison of the obesity rate $(r)$ showed an unexpected result with the growth of diabetes as for the years from 2011 to 2016 and regions. This correlation was less expected at the level of (0.58).

Comparing the results (from 2004-2008) obtained in a similar investigation, it can be noted that the situation in some regions at that time was somewhat different in the territory of Kazakhstan. Regions with high rates in 2008 are Almaty city (118.5), Astana city (135.5) and Mangystau city (139.7).

The regions with the highest incidence of obesity by the end of 2016 were South-Kazakhstan (146.2), Astana city (144.0) and Almaty city (123.8).

In 2004-2008, the number of firstly registered patients with obesity accounted for 54,228. In 2011-2016 this figure reached 67,324 .

\section{Conclusion}

The investigation revealed a steady increase in obesity, diabetes, metabolic and nutritional disorders from 20112016. The annual increase in obesity rates during the study period amounted to 3.9 per cent. The highest correlation (Pearson) of obesity value and diabetes is $(r, 0.96)$.

\section{References}

1. The World Health Organization (WHO). Obesity and overweight. Fact sheet. Accessed October, 2017 http://www.who.int/mediacentre/factsheets/fs311/en/

2. National genetic register of Kazakhstan 2017 https://www.medelement.com/ Accessed May 01, 2017. 
3. National health care development programme of Kazakhstan «Densaulyk» 2016-2019. Astana: 2016: 4. http://www.enbek.gov.kz/ru/node/332663 Accessed January 01, 2017.

4. CIA World Factbook. https://www.cia.gov/library/publications/resources/theworld-factbook/geos/kz.html Accessed Sept.06, 2017.

5. Health of population in Kazakhstan and health care organisations activities in 2011. Statistic deference. Astana: 2012:320.

6. Statistics committee of Kazakhstan National economic ministry. Official statistical data. References. Quarterly editions. Electronic tables. Analytics. Health Care, Archive; 2012.

www.stat.gov.kz/faces/wcnav_externalld/home (Numbers Health Care Accessed November 27, 2016).

7. Statistics committee of Kazakhstan National economic ministry. Official statistical data. References. Quarterly editions. Electronic tables. Analytics. Health Care, Archive; 2015.

http://www.stat.gov.kz/faces/wcnav_externalld/home (Numbers Health Care Accessed December 01, 2016).

8. Statistics committee of Kazakhstan National economic ministry. Official statistical data. References. Quarterly editions. Electronic tables. Analytics. Health Care, Archive; 2016.

http://www.stat.gov.kz/faces/wcnav_externalld/home (Numbers Health Care Accessed December 23, 2016).

9. Demographic annual statistical reference. Astana: 2011:592.

\section{ACKNOWLEDGEMENTS}

The authors are grateful to the staff of medical organizations of Kazakhstan for essential contribution to the realization of the State Program "Health of Kazakhstan". Furthermore, they are pleased to all branches of primary sections in regions, the National Centre for Healthy Lifestyle Development, the Republican Center for Health Development, for the popularization of morbidity prevention.

\section{PEER REVIEW}

Not commissioned. Externally peer reviewed.

\section{CONFLICTS OF INTEREST}

The authors declare that they have no competing interests.

\section{ETHICS COMMITTEE APPROVAL}

The proceeding paper for investigation related to obesity problems was approved by the Ethics Research Committee of the Medical University (№1, jan. 25, 2014 and №3, Dec. 24, 2015).

\section{FUNDING}

None 
Table 1: Morbidity of diabetes and obesity in Kazakhstan (the number of diseases registered for the first time per 100000 people in 2011 and 2016)

\begin{tabular}{|c|c|c|c|c|c|c|c|c|}
\hline \multirow{2}{*}{$\begin{array}{l}\text { Category of } \\
\text { population }\end{array}$} & \multicolumn{2}{|c|}{ Total morbidity $^{\dagger}$} & \multicolumn{2}{|c|}{ Diabetes* } & \multicolumn{2}{|c|}{$\begin{array}{c}\text { Overweight and } \\
\text { obesity* }^{*}\end{array}$} & \multicolumn{2}{|c|}{ Obesity* } \\
\hline & 2011 & 2016 & 2011 & 2016 & 2011 & 2016 & 2011 & 2016 \\
\hline $\begin{array}{l}\text { Rural } \\
\text { (\% from total } \\
\text { morbidity) }\end{array}$ & $\begin{array}{l}575.4 \\
(11.2) \\
100 \%\end{array}$ & $\begin{array}{l}575.8 \\
(10) \\
100 \%\end{array}$ & $\begin{array}{l}116.1 \\
(8.1) \\
20.20 \%\end{array}$ & $\begin{array}{l}138.4 \\
(7.2) \\
23.50 \%\end{array}$ & $\begin{array}{l}115.9 \\
(7.4) \\
20.10 \%\end{array}$ & $\begin{array}{l}140.3 \\
(5.3) \\
24.40 \%\end{array}$ & $\begin{array}{l}59.2 \\
(2.1) \\
10.30 \%\end{array}$ & $\begin{array}{l}79.5 \\
(2.1) \\
13.80 \%\end{array}$ \\
\hline $\begin{array}{l}\text { Urban } \\
\text { (\% from total } \\
\text { morbidity) }\end{array}$ & $\begin{array}{l}1269.5 \\
(23.1) \\
100 \%\end{array}$ & $\begin{array}{l}1104.8 \\
(17.1) \\
100 \%\end{array}$ & $\begin{array}{l}193.5 \\
(5.2) \\
15.20 \%\end{array}$ & $\begin{array}{l}198.7 \\
(3.2) \\
18.00 \%\end{array}$ & $\begin{array}{l}197.4 \\
(2.4) \\
15.50 \%\end{array}$ & $\begin{array}{l}203.1 \\
(2.6) \\
18.40 \%\end{array}$ & $\begin{array}{l}88.4 \\
(2.2) \\
7.00 \%\end{array}$ & $\begin{array}{l}96.3 \\
(1.8) \\
8.70 \%\end{array}$ \\
\hline Women & 1142,5 & 1110,9 & 185,5 & 217,8 & 188,9 & 200,2 & 112,3 & 138,5 \\
\hline Men & 800,3 & 809,9 & 125,8 & 143,2 & 123,8 & 162,2 & 89,5 & 95,3 \\
\hline $\begin{array}{l}\text { Patients } 18 \text { years and } \\
\text { older }\end{array}$ & 789,9 & 821,1 & 220,5 & 245,3 & 225,2 & 233,1 & 225,9 & 253,1 \\
\hline $\begin{array}{l}\text { Patients 15-17 years } \\
\text { old }\end{array}$ & 2128,4 & 1892,2 & 12,5 & 14,2 & 12,7 & 13,2 & 12,9 & 15,8 \\
\hline Patients $0-14$ years old & 1250 & 875,1 & 9,7 & 10,2 & 10,1 & 11,1 & 10,5 & 13,7 \\
\hline $\begin{array}{l}\text { The average for } \\
\text { country }\end{array}$ & $\begin{array}{l}954,3 \\
(12.1)\end{array}$ & $\begin{array}{l}877.6 \\
(10.1)\end{array}$ & $\begin{array}{l}158,3 \\
(8.1)\end{array}$ & $\begin{array}{l}173,1 \\
(7.1)\end{array}$ & $\begin{array}{l}161,1 \\
(7.0)\end{array}$ & $\begin{array}{l}180,7 \\
(5.2)\end{array}$ & $\begin{array}{l}73.8 \\
(2.3)\end{array}$ & $\begin{array}{l}91.2 \\
(2.3)\end{array}$ \\
\hline $\begin{array}{l}\text { Annual increase in the } \\
\text { country (R., \%) }\end{array}$ & & $-2,2$ & & $+1,6$ & & $+2,0$ & & $+3,9$ \\
\hline
\end{tabular}

$\boldsymbol{t}$-diseases of the endocrine system, metabolic disorders;

*-number of diseases (SD), registered for the first time, per 100,000 people of the population with a confidential interval of $95 \%$ and a statistical significance level, $p \leq 0.05$, considering the statistical reports 4,050 medical organizations 